\title{
Oxygen Diffusion Through Natural Extracellular Matrices: Implications for Estimating "Critical Thickness" Values in Tendon Tissue Engineering
}

\author{
Caroline Androjna \\ Cleveland Clinic \\ Jorge E. Gatica \\ Cleveland State University \\ Joanne M. Belovich

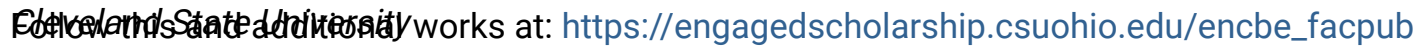

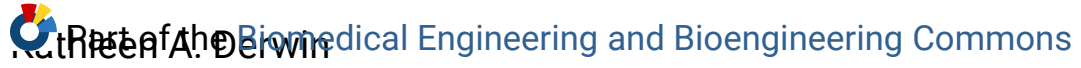 \\ Alekeldodsclicioess to this work benefit you? Let us know!

\section{Publisher's Statement} \\ This is a copy of an article published in Tissue Engineering Part A; @ 2008 Mary Ann Liebert, \\ Inc.; Tissue Engineering is available online at: http://www.liebertonline.com.
}

\section{Original Citation}

Androjna, Caroline; Gatica, Jorge E.; Belovich, Joanne M.; Derwin, Kathleen A.. (2008). Oxygen Diffusion Through Natural Extracellular Matrices: Implications for Estimating "Critical Thickness" Values in Tendon Tissue Engineering. Tissue Engineering Part A 14, 559-569.

\section{Repository Citation}

Androjna, Caroline; Gatica, Jorge E.; Belovich, Joanne M.; and Derwin, Kathleen A., "Oxygen Diffusion Through Natural Extracellular Matrices: Implications for Estimating "Critical Thickness" Values in Tendon Tissue Engineering" (2008). Chemical \& Biomedical Engineering Faculty Publications. 19.

https://engagedscholarship.csuohio.edu/encbe_facpub/19

This Article is brought to you for free and open access by the Chemical \& Biomedical Engineering Department at EngagedScholarship@CSU. It has been accepted for inclusion in Chemical \& Biomedical Engineering Faculty Publications by an authorized administrator of EngagedScholarship@CSU. For more information, please contact library.es@csuohio.edu. 


\title{
Oxygen Diffusion through Natural Extracellular Matrices: Implications for Estimating "Critical Thickness" Values in Tendon Tissue Engineering
}

\author{
CAROLINE ANDROJNA, Ph.D., ${ }^{1}$ JORGE E. GATICA, Ph.D., \\ JOANNE M. BELOVICH, Ph.D., 2,* and KATHLEEN A. DERWIN, Ph.D., ${ }^{1 *}$
}

\begin{abstract}
Oxygen is necessary for maintaining cell proliferation and viability and extracellular matrix (ECM) production in 3-dimensional tissue engineering. Typically, diffusion is the primary mode for oxygen transport in vitro; thus, ensuring an adequate oxygen supply is essential. In this study, we determined the oxygen diffusion coefficients of 3 natural ECMs that are being investigated as construct scaffolds for tendon tissue engineering: small-intestine submucosa (SIS), human dermis (Alloderm ${ }^{\circledR}$ ), and canine fascia lata. Diffusion coefficients were determined using a standard diffusion cell system. The ranges for each matrix type were: SIS: $7 \times 10^{-6}-2 \times 10^{-5} \mathrm{~cm}^{2} / \mathrm{s}$, Alloderm ${ }^{-}: 1.9-3.1 \times 10^{-5} \mathrm{~cm}^{2} / \mathrm{s}$, and canine fascia lata: $1.6-4 \times 10^{-5} \mathrm{~cm}^{2} / \mathrm{s}$. We used the experimental oxygen diffusivity data for these natural ECMs in a mathematical model of oxygen diffusion through a cell-seeded scaffold to estimate the critical size of cellseeded scaffold that can be cultured in vitro.
\end{abstract}

\section{INTRODUCTION}

W HEN DESIGNING ENGINEERED tissue replacements in vitro, efforts tend to be expended on the selection of scaffold materials and cells and the addition of chemical or mechanical signals. Providing an optimal culture environment is also essential. Basic culture requirements that must be met include adequate cell nutrition, oxygenation, and addition of tissue-specific chemical and physical regulatory signals. Although all are important for cell viability, proliferation, and extracellular matrix production, oxygen availability is the most challenging design parameter because of the low solubility and rate of diffusion of oxygen within culture medium and scaffold biomaterials. ${ }^{1-5}$

In vivo, the circulatory system provides appropriate gradients of oxygen, nutrients, and regulatory molecules to tissues via convective and diffusive transport. In vitro, the delivery of oxygen within tissue-engineered constructs primarily occurs via diffusive transport over larger distances, because oxygen is provided at the construct surface only. The amount of available oxygen will decrease from the surface to the center of the construct, limiting the size that may be adequately cultured. Quantifying the diffusive transport of oxygen within tissue-engineered tendon constructs is essential for maintaining cell viability throughout the construct.

A major factor that can influence oxygen delivery to a cell-seeded tissue-engineered tendon construct is the diffusivity of oxygen through the scaffold biomaterial, which can be characterized according to the material's diffusion coefficient parameter. For a tissue-engineered construct, this parameter will depend greatly on the scaffold's porosity and tortuosity. The value of this parameter determines the maximum tissue thickness (critical thickness) that

\footnotetext{
${ }^{1}$ Department of Biomedical Engineering, The Cleveland Clinic, Cleveland, Ohio.

${ }^{2}$ Department of Chemical and Biomedical Engineering, Cleveland State University, Cleveland, Ohio.

*These senior authors' contributing efforts were equal in this research work.
} 
precludes oxygen limitation and thus necrosis anywhere in the construct during long-term in vitro culture. Because oxygen availability throughout the tissue is a key element in the development of tissue-engineered constructs, estimates of oxygen diffusivity through potential scaffolds are needed.

The main objective this study was to determine the oxygen diffusion coefficient through 3 natural extracellular matrices (ECMs) being investigated as scaffolds for tendon tissue engineering in our laboratory: small-intestine submucosa (SIS), human dermis (Alloderm ${ }^{\circledR}$, LifeCell Corporation, Branchburg, NJ), and canine fascia lata. Although each matrix provides inherent biologic or mechanical properties, making it an attractive tendon replacement, further tissueengineering strategies that include cell-seeding and in vitro mechanical stimulation to enhance their properties at implantation as well as deliver cells expressing a desired phenotype are being investigated. Thus, as a second objective of this work, we have modeled oxygen diffusion through a cellseeded scaffold. From the mathematical model and experimental oxygen diffusivity data, we can estimate the critical size of a cell-seeded scaffold that can be adequately oxygenated and maintained during a long-term in vitro culture period.

\section{MATERIALS AND METHODS}

\section{ECM scaffold preparation}

Processing of a devitalized and largely acellularized SIS matrix from a porcine animal source has been previously described. ${ }^{6,7}$ Briefly, the SIS was prepared from the small intestine of market-weight pigs $(\sim 120 \mathrm{~kg})$ harvested immediately after euthanasia. The small intestine was mechanically delaminated to remove the tunica muscularis externa, the tunica mucosa, and the stratum compactum. The multilaminate layer that remains is the tunica submucosa, with a thickness of approximately 80 to $100 \mu \mathrm{m}^{6,7}$ and consisting of ECM and some cellular remnants. This submucosal layer was disinfected in a $0.1 \%$ peracetic acid solution followed by 2 rinses each in phosphate buffered saline (PBS) and deionized water. The SIS was then lyophilized and terminally sterilized with 2 Mrad of gamma irradiation.

Alloderm ${ }^{\circledR}$ is manufactured by LifeCell Corporation and is derived from human allograft skin that is processed using a patented technique to remove the epidermis, cells, and cell remnants. To preserve the acellularized dermal layer, a proprietary freeze-drying method is used that retains the native extracellular architecture and vascular channels. The matrix contains biochemical components, including collagen, elastin, and proteoglycans, and is not artificially crosslinked. It is packaged dry. The material is a single layer and is provided in a variety of thicknesses $(0.5-2 \mathrm{~mm})$ and sizes for targeted surgical indications.

Fresh fascia lata were retrieved from canines at sacrifice from an unrelated study at our institution. A fascia patch was harvested from the distal portion of the fascia lata in a region corresponding to the iliotibial tract. Fascia patches were cleaned of extraneous fat and muscle under aseptic conditions. The fascia lata samples were frozen in salinemoist gauze at $-20^{\circ} \mathrm{C}$ to devitalize the tissue and stored at this temperature until analyzed for oxygen diffusivity.

For oxygen diffusivity measurements, the SIS and Alloderm ${ }^{\circledR}$ samples were re-hydrated in low-glucose Dulbecco's modified Eagle medium (DMEM-LG) supplemented with $10 \%$ fetal bovine serum (FBS) and $1 \%$ antibiotic/ antimycotic solution (AB/AM) overnight in $5 \%$ carbon dioxide $\left(\mathrm{CO}_{2}\right)$ at $37^{\circ} \mathrm{C}$. The canine fascia lata samples were first thawed in $1 \times$ phosphate buffered saline (PBS) supplemented with $1 \% \mathrm{AB} / \mathrm{AM}$ overnight at $4{ }^{\circ} \mathrm{C}$ and then transferred to DMEM-LG supplemented with $10 \% \mathrm{FBS}$ and $1 \% \mathrm{AB} / \mathrm{AM}$ and equilibrated in $5 \% \mathrm{CO}_{2}$ at $37^{\circ} \mathrm{C}$ for several hours. Under sterile conditions, the ECMs were cut into 30-mm circular samples and placed into a specially designed holder device $(\mathrm{d}=2.14 \mathrm{~cm})$ as shown in Figure 1. The available area for membrane diffusion was $3.6 \mathrm{~cm}^{2}$.

\section{Oxygen diffusion measurements}

The oxygen diffusion coefficients were measured in processed SIS $(n=6)$, Alloderm ${ }^{\circledR}(n=4)$, and fresh-frozen canine fascia lata $(n=4)$ samples using a conventional diffusion system (Crown Glass, Somerville, NJ) (Fig. 2). The system consisted of 2 well-stirred compartments that contained known (measured) concentrations of oxygen, separated by the ECM scaffold of interest. Oxygen concentrations were measured using a CellOx 325 probe (WTW Measurement Systems Inc., Gold River, CA). Air was continuously sparged into the donor compartment, maintaining fully saturated oxygen levels in this compartment throughout the experiment. The average of the initial and final oxygen concentration readings in the donor compartment was used for diffusivity data analysis $\left(C_{D}\right)$. Oxygen concentrations were measured in the receiver compartment at 10-min intervals. Each membrane was tested 3 times consecutively in DMEM-LG supplemented with $15 \mathrm{mM} \mathrm{N}-2-$ hydroxyethylpiperazine- $\mathrm{N}^{\prime}$-2-ethanesulfonic acid (HEPES), $1 \% \mathrm{FBS}$, and $1 \% \mathrm{AB} / \mathrm{AM}$. The diffusion system temperature was maintained at $37^{\circ} \mathrm{C}$ via a thermostatically controlled water bath. Each run took approximately $10 \mathrm{~h}$. A typical dataset is depicted in Figure 3A.
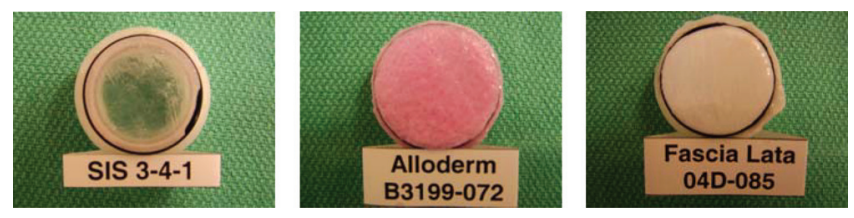

FIG. 1. Representative extracellular matrices in the customdesigned holder device. Color images available online at www .liebertpub.com/ten. 

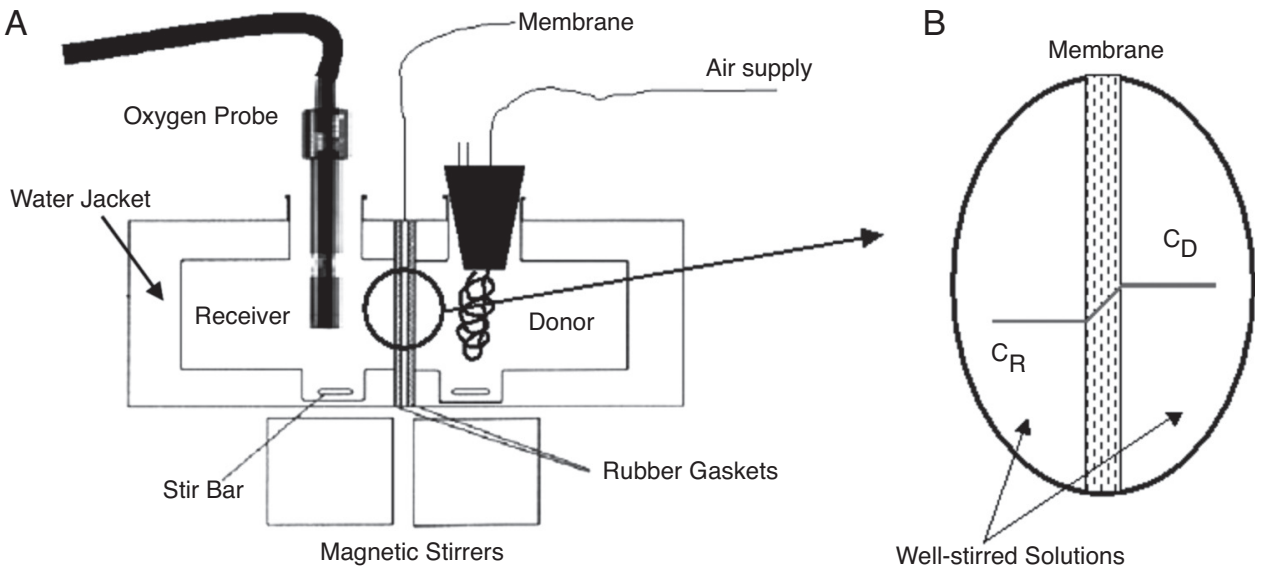

FIG. 2. (A) Schematic of the experimental diffusion system. (B) The solute (e.g., oxygen) diffuses across the membrane from the donor to the receiver compartment.

Inherent to our experimental system was an artifactual oxygen source flux that needed to be accounted for. This baseline volumetric oxygen diffusion value likely resulted from air bubbles produced at the experimental onset during nitrogen sparging of the receiver compartment and ambient air being introduced on the receiver side through the dissolved oxygen probe inlet port. This baseline oxygen diffusion value was measured using a solid rubber plug between the donor and receiver compartments in place of the ECM membrane. The average of 7 trials was taken and assumed to be representative of the baseline effect that occurred during the scaffold diffusion experiments (Fig. 3B).

\section{ECM scaffold thickness measurements}

A constant-pressure linear variable differential transducer (LVDT) probe $\left(0.07 \mathrm{~cm}^{2}\right.$ contact area) was used to estimate the wet tissue thickness. The thickness measures were made on the wet scaffold samples after the completion of the diffusion experiment. Thickness was estimated from the average of measurements made at 8 locations across the diffusion area, representing a $15 \%$ $\left(0.6 \mathrm{~cm}^{2}\right)$ sampling of the diffusion area. The applied stress of the LVDT probe on the membrane was approximately $0.001 \mathrm{MPa}$ and resulted in only minimal indentation of the scaffold materials.

\section{Data analysis}

The mathematical model of the typical experimental diffusion system is well established. ${ }^{8}$ However, the experimental procedure considered in this work deviated from the standard procedure because the donor oxygen concentration was maintained constant and experimental evidence, as
A

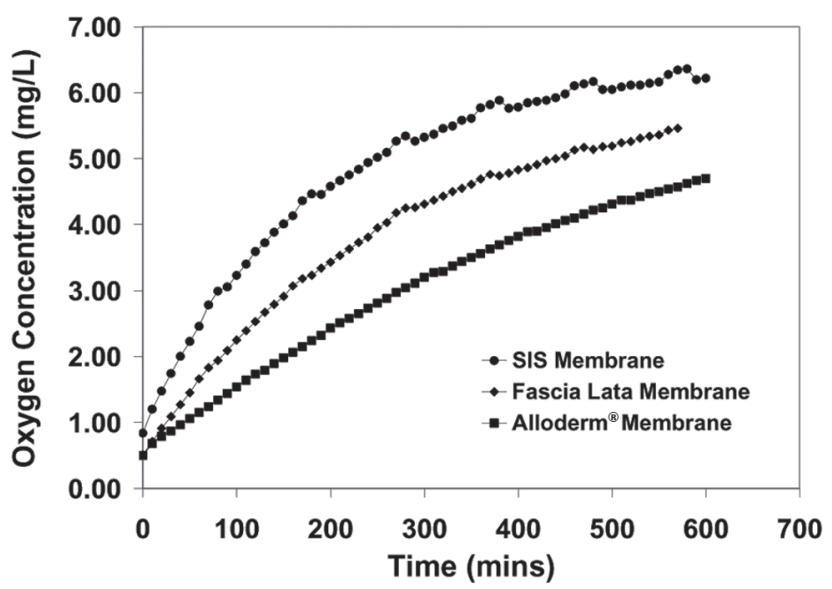

B

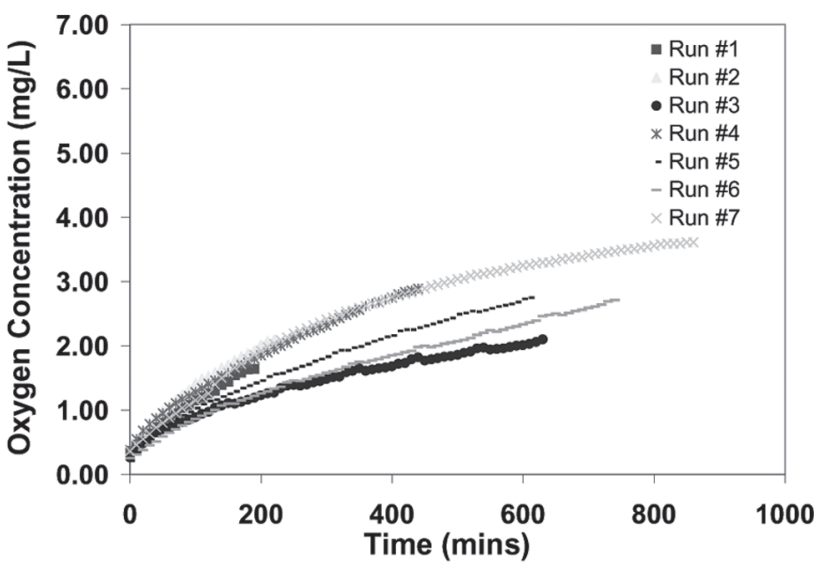

FIG. 3. (A) Representative data of oxygen concentration values over time within the receiver compartment for the different membrane types. (B) Oxygen concentration values over time representative of the experimental baseline effect. 
described above, pointed to the presence of a baseline flux process in the system that needed to be considered here. Therefore, the model equations from Cussler et al. ${ }^{8}$ were adapted to these experimental conditions, yielding:

$$
\begin{gathered}
V^{R} \frac{d c^{R}}{d t}=+A_{M j_{M}}+Q_{B} \\
j_{M}=\frac{\mathcal{D}_{e, M}}{l}\left(c_{D}-c_{R}\right) \\
Q_{B}=D_{B}\left(c^{*}-c_{R}\right)
\end{gathered}
$$

Equation 1 describes the time-dependent change of the oxygen concentration $\left(c_{R}, \mathrm{mg} / \mathrm{L}\right)$ in the receiver compartment, where $V_{R}$ denotes the fluid volume (L) in the receiver compartment, $t$ represents time (s), $A_{M}$ is the available membrane surface area $\left(\mathrm{cm}^{2}\right)$ for diffusion, $j_{M}$ represents the oxygen flux through the membrane per unit area $(\mathrm{mg} /$ $\mathrm{cm}^{2} \mathrm{~s}$ ), and $Q_{B}$ represents the experimental baseline input rate of oxygen $(\mathrm{mg} / \mathrm{s})$. Equation 2 describes the pseudosteady-state flux of oxygen $\left(j_{M}\right)$ across the semipermeable membrane, where $\mathcal{D}_{\mathrm{e}, \mathrm{M}}$ is the effective membrane oxygendiffusion coefficient $\left(\mathrm{cm}^{2} / \mathrm{s}\right), l$ is the membrane thickness $(\mathrm{cm})$, and $c_{D}$ is the constant oxygen concentration in the donor compartment $(\mathrm{mg} / \mathrm{L})$. Equation 3 describes the experimental baseline oxygen flux $\left(Q_{B}\right)$, which is assumed to be a linear effect, where $D_{B}$ is the experimental baseline volumetric oxygen diffusion factor $(\mathrm{L} / \mathrm{s})$. The parameter, $c^{*}$, is the maximum amount of oxygen soluble in solution. Because the donor cell represents a saturated oxygen solution, it can be assumed that $c^{*}$ is the same as the oxygen concentration $\left(c_{D}\right)$ measured within the donor cell. Thus Equation 3 can be rewritten as:

$$
Q_{B}=D_{B}\left(c_{D}-c_{R}\right)
$$

Combining Equations 1, 2, and 3a yields:

$$
\frac{d c_{R}}{\left(c_{D}-c_{R}\right)}=\mathcal{D}^{\prime} d t
$$

in which

$$
\mathcal{D}^{\prime}=\beta^{\prime} \mathcal{D}_{e, M}+\frac{D_{B}}{V_{R}}
$$

and

$$
\beta^{\prime}=\frac{A_{M}}{l V_{R}}
$$

where $\mathcal{D}^{\prime}$ is the diffusion factor of the system $\left(\mathrm{s}^{-1}\right)$ and $\beta^{\prime}$ is the effective membrane characteristic geometric constant $\left(\mathrm{cm}^{-2}\right)$. The differential equation is subject to the following initial condition:

$$
\text { at } t=0, c_{R}=c_{R o}
$$

Integrating Equation 4 results in:

$$
\ln \left(\frac{c_{D}-c_{R o}}{c_{D}-c_{R}}\right)=\mathcal{D}^{\prime} t
$$

The system diffusion factor $\left(\mathcal{D}^{\prime}\right)$ was calculated for each dataset from the slope of the experimental logarithmic concentration data versus time (Equation 5), using a onesided least squares sensitivity analysis. ${ }^{9}$ Briefly, the slope and the error associated with the regression of the data points were calculated. The sensitivity of the standard error for the slope to the elimination of later (right-sided sensitivity) points was then analyzed. The set of points that yielded the most reliable estimate (the minimum standard error) of the slope was thus identified. For significance purposes, a minimum set of $50 \%$ of the data points were used in these calculations. The data were fit between $0.5 \mathrm{~h}$ to $6 \mathrm{~h}$ for each membrane. Because the initial $30 \mathrm{~min}$ of data corresponded to the time required to reach the quasi steadystate oxygen diffusion regime, these data were not included in the analysis. A typical dataset and the key parameters identified using the least-squares analysis are depicted in Figure 4.

The baseline volumetric diffusion factor $\left(D_{B}\right)$ was determined from the oxygen concentration data in which the ECM membrane was replaced with the nonpermeable rubber plug (Fig. 3B).

Because $\mathcal{D}_{e, M}=0$ in this case, Equation 5 can be written as:

$$
\ln \left(\frac{c_{D}-c_{R o}}{c_{D}-c_{R}}\right)=\frac{D_{B}}{V_{R}} t
$$

and Equation 4a can be rearranged to:

$$
\mathcal{D}_{e, M}=\frac{1}{\beta}\left(\mathcal{D}^{\prime}-\frac{D_{B}}{V_{R}}\right)
$$

$D_{B}$ is obtained by applying Equation 6 to the data in Figure $3 \mathrm{~B}$ in a manner similar to that described in the previous paragraph. Because the baseline effect should be independent of the specific membrane, the mean baseline $\left(D_{B}\right)$ value was used, along with the membrane-specific $D^{\prime}$, to calculate the effective diffusion coefficient for each membrane $\left(\mathcal{D}_{e, M}\right)$ from Equation 7 .

\section{Statistics}

To account for the variability in the experimental measures (e.g., large variation in membrane thickness values), the standard errors for the effective membrane oxygen 


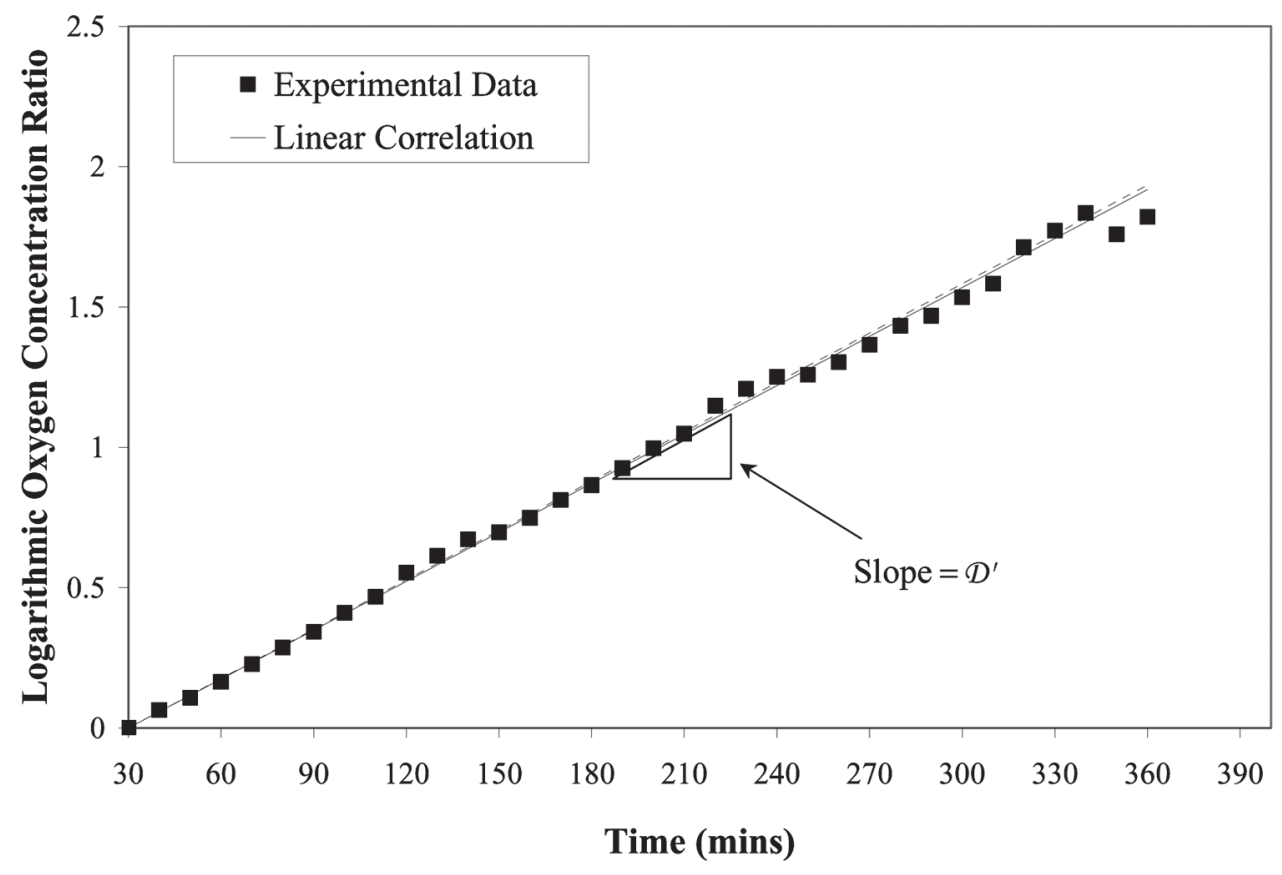

FIG. 4. Typical linear regression analysis of the experimental oxygen data.

diffusion coefficients $\left(\mathcal{D}_{\mathrm{e}, \mathrm{M}}\right)$ were calculated using standard error propagation techniques. ${ }^{10}$ Specifically, propagation errors for variation in membrane thickness, data regression of $\mathcal{D}^{\prime}$ among replicates, and experimental error generated by the baseline effect $\left(D_{B}\right)$ were determined. Statistical analyses of the diffusion coefficients were performed using analysis of variance (ANOVA) techniques with post hoc multiple comparisons tests (Tukey-Kramer and Dunn methods). Differences were considered statistically significant if the corresponding ANOVA $P$-value $\leq 0.05$. All analyses were completed using SigmaStat for Windows, v3.10 (Systat Software, Inc., Chicago, IL).

\section{Critical construct-thickness model}

The dynamics of oxygenation within a bioreactor culture system result from the interaction of 3 factors: the solubility of oxygen in the culture medium, oxygen diffusivity through the medium and cell-seeded scaffold, and the oxygen consumption by the cells. A schematic of a cell-seeded rectangularshaped scaffold, viewed from the side and oriented as in our current bioreactor system, is shown in Figure 5A. The bulk oxygen concentration $\left(c_{S b}\right)$ of the medium is dependent upon the particular bioreactor or culture system design. To optimize available oxygen at the tissue-medium interface, in this static culture system, our reactor chambers include silicone gas-permeable membranes $(\sim 127 \pm 76 \mu$ m thick, SF Medical, McMaster-Carr, Aurora, $\mathrm{OH}$ ) placed on the front and back halves of the reactor to provide oxygen to both sides of the tissue. Thus, the cell-seeded scaffold is bathed and surrounded on all sides with surface-aerated culture medium. The transport of oxygen through half of the scaffold (Fig. 5B) can be modeled using the diffusion-reaction equation. Although the concentration of oxygen in the scaffold is a function of all space dimensions, meeting the oxygen requirements in the direction of the steepest concentration gradient (thickness, denoted by $z$ ) will ensure adequate oxygenation throughout the scaffold. By assuming steady-state oxygen transport, an isotropic diffusion tensor, and a homogenous distribution of cells within the scaffold, the mass balance on oxygen in the scaffold is given as:

$$
\mathcal{D}_{e, M} \frac{d^{2} c_{O_{2}}}{d z^{2}}=r_{O_{2}}
$$

where $\mathcal{D}_{\mathrm{e}, \mathrm{M}}$ is the effective membrane oxygen-diffusion coefficient $\left(\mathrm{cm}^{2} / \mathrm{s}\right), \mathrm{z}$ is the distance $(\mathrm{cm}), c_{O 2}$ the local oxygen concentration at a specific $\mathrm{z}\left(\mathrm{mmol} \mathrm{O}_{2} / \mathrm{L}\right)$, and $r_{\mathrm{O} 2}$ the volumetric oxygen uptake rate of the cells $\left(\mathrm{mmol} \mathrm{O}_{2} / \mathrm{h}\right.$ per $\mathrm{mL}$ ).

For the boundary conditions, it is assumed that there is no oxygen flux at the scaffold's central plane and the oxygen concentration at the medium-scaffold interface is the same as the oxygen concentration of the bulk medium $\left(c_{S b}\right)$. Because the area of the silicone window $\left(8 \mathrm{~cm}^{2}\right)$ is at least as large as the scaffold surface area $\left(3 \mathrm{~cm}^{2}\right)$, it is reasonable to assume that $c_{S b}$ is independent of fluid height in the reactor. These boundary conditions are expressed as:

$$
\text { @ } z=0, \quad \frac{d c_{O_{2}}}{d z}=0
$$


A

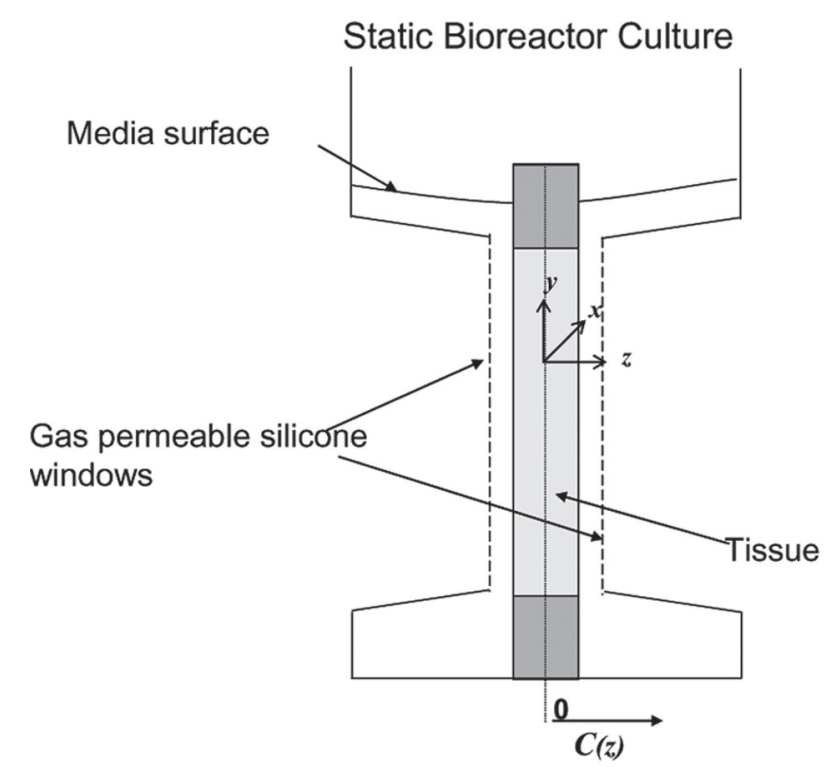

B

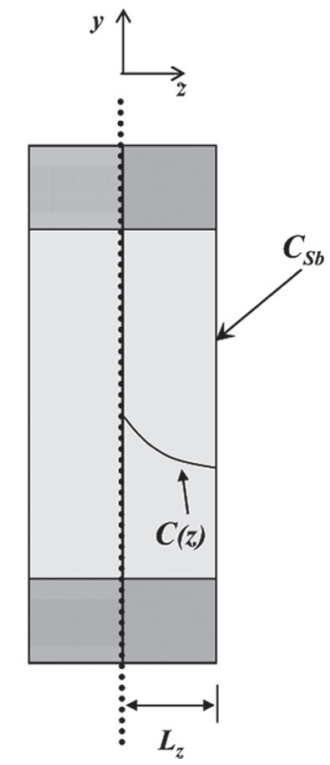

FIG. 5. (A) Schematic of the medium-bathed cell-seeded scaffold in a static bioreactor system. (B) Schematic of the cell-seeded scaffold: $c(z)$ represents the oxygen profile through the scaffold as a function of oxygen available at the surface $\left(c_{S b}\right)$, and $L_{z}$ is representative of half of the total scaffold thickness.

$$
\text { @ } z=L_{z}, \quad c(z)=c_{S b}
$$

Assuming that oxygen levels within the bioreactor will be maintained above critical oxygen levels, one can assume that the oxygen consumption rate is represented by zeroorder kinetics:

$$
r_{O_{2}}=q_{O_{2}} X
$$

Where $q_{O 2}$ is the specific cellular oxygen uptake rate (mol $\mathrm{O}_{2} / \mathrm{h}$ per cell), and $X$ is the cell density of the cell-seeded scaffold (cells $/ \mathrm{mL}$ ).

Integrating Equation 8 results in the oxygen concentration profile:

$$
c_{O_{2}}(z)=\frac{q_{O_{2}} X}{2 \mathcal{D}_{e, M}}\left(z^{2}-L_{z}^{2}\right)+c_{S b}
$$

The critical thickness is defined as the total thickness (i.e. $\left.2 L_{z, \text { Critical. }}\right)$ of a cell-seeded scaffold that would be adequately oxygenated via diffusive transport in vitro. This is evaluated by setting the minimum oxygen concentration in the scaffold $\left(c_{\mathrm{O} 2}\right.$ at $\left.z=0\right)$ equal to the critical oxygen concentration needed to maintain viability and proliferation $\left(c_{O 2, \text { Critical }}\right)$ in Equation 10 . Thus, $2 L_{z, \text { Critical. }}$ is given as:

$$
2 L_{z, \text { Critical }}=2 \sqrt{\frac{2 \mathcal{D}_{e, M}\left(c_{S b}-c_{O_{2}, \text { Critical }}\right)}{q_{O_{2}} X}}
$$

To estimate critical scaffold thicknesses for the ECM materials investigated in this study, the following variable assignments were made; the ECM scaffold material contained marrow stromal cells (MSCs) at a density (X) of $2.75 \times 10^{7}$ cells $/ \mathrm{mL}$, which is the near-maximum cell concentration that would be expected to be achieved in a scaffold; the oxygen consumption rate $\left(q_{\mathrm{O}_{2}}\right)$ of the MSCs was $3.15 \times 10^{-11} \mathrm{mmol} \mathrm{O} / \mathrm{h}$ per cell $;^{5}$ the maximum value for $c_{S b}$ was varied between $30 \%$ and $100 \%$ of the maximum saturation value of oxygen $\left(\mathrm{c}^{*}\right)$ in a protein solution, previously determined as $0.217 \mathrm{mmol} \mathrm{O}_{2} / \mathrm{L} ;{ }^{5}$ and the critical oxygen concentration $\left(c_{O 2}\right.$, Critical $)$ was set to $10 \%$ of $c^{*}$, although for mammalian cell cultures, it has been shown to be as low as $1 \%$ to $5 \%$ of maximum oxygen saturation values in solution. ${ }^{2,5}$ From the experimental oxygen diffusion data, we utilized the smallest value of $\mathcal{D}_{\text {e.M }}$ measured across all samples for each ECM material, thereby making a conservative estimate for the critical tissue thickness.

\section{RESULTS}

\section{ECM scaffold thickness}

The thickness of the ECM scaffolds varied considerably between materials, as well as between pieces of the same material and even across the $3.6-\mathrm{cm}^{2}$ diffusion area of a given sample (Table 1). The mean value of the 8 thickness measures for each sample was used in the determination of effective membrane diffusion coefficients. 
Table 1. Scaffold Thickness

\begin{tabular}{|c|c|c|c|c|c|c|}
\hline \multirow[b]{2}{*}{ Sample } & \multicolumn{2}{|c|}{ SIS } & \multicolumn{2}{|c|}{ Alloderm ${ }^{\circledR}$} & \multicolumn{2}{|c|}{ Fascia Lata } \\
\hline & Mean $\pm S D(\mu m)$ & Range $(\mu m)$ & Mean $\pm S D(\mu m)$ & Range $(\mu m)$ & Mean $\pm S D(\mu m)$ & Range $(\mu \mathrm{m})$ \\
\hline 1 & $193 \pm 45$ & $138-266$ & $1393 \pm 53$ & $1306-1460$ & $677 \pm 109$ & $558-854$ \\
\hline 2 & $107 \pm 47$ & $60-169$ & $1035 \pm 63$ & 934-1098 & $472 \pm 74$ & $382-632$ \\
\hline 3 & $85 \pm 21$ & $43-113$ & $1211 \pm 103$ & $997-1305$ & $817 \pm 65$ & 719-894 \\
\hline 4 & $63 \pm 23$ & $34-107$ & $1204 \pm 52$ & $1134-1281$ & $599 \pm 72$ & $488-681$ \\
\hline 5 & $64 \pm 42$ & $34-162$ & & & & \\
\hline 6 & $66 \pm 17$ & $41-84$ & & & & \\
\hline
\end{tabular}

(Mean \pm standard deviation and range of 8 measures per sample)

\section{Baseline diffusion coefficient $\left(\mathrm{D}_{\mathrm{B}}\right)$}

The average baseline diffusion coefficient was found to be $8.5 \pm 2.3 \times 10^{-4} \mathrm{~mL} / \mathrm{s}$. This value was used to adjust the measured membrane diffusion coefficients according to Equation 7.

\section{Effective membrane diffusion coefficient $\left(\mathcal{D}_{e, M}\right)$}

The mean effective membrane diffusion coefficients of the 3 trial runs for each ECM scaffold sample are presented in Table 2. As expected, most of the values were consistent with the model assumption that membrane diffusion was the transport-limiting step. Indeed, most of the effective diffusivities were lower than the oxygen diffusivity in water $\left(3.83 \times 10^{-5} \mathrm{~cm}^{2} / \mathrm{s}\right.$ at $\left.37^{\circ} \mathrm{C}^{2}\right)$. One exception is Sample 1 of Alloderm ${ }^{\circledR}$, whose calculated diffusivity value was $1.1 \pm 0.1 \times 10^{-4} \mathrm{~cm}^{2} / \mathrm{s}$ (§ Table 2). During experimental setup, this sample was observed to be "sweating" excessively, indicating that fluid was moving easily through it. This phenomenon was not seen for any of the other ECM samples and suggests that the diffusivity for this particular Alloderm ${ }^{\circledR}$ sample was a function of diffusive and convective transport of oxygen. Consequently, the experimental conditions for this sample were not consistent with the assumptions of the diffusion cell model. The diffusion coefficient for this sample is reported in Table 2 for demonstrative purposes only but was not considered in the subsequent statistical analyses (Table 3). The calculated diffusion coefficients for all other samples listed in Table 2 were less than or within experimental error of the value reported for the diffusivity of oxygen in water.

The repeated measures for each membrane were found to be normally distributed. Thus, repeated-measures ANOVA with Tukey-Kramer post hoc multiple comparisons was completed to assess whether there were any differences within the same ECM membrane type. The variability in diffusivity values between samples of the same ECM was highly significant for SIS $\left(7 \times 10^{-6}-2 \times 10^{-5} \mathrm{~cm}^{2} / \mathrm{s} ; p<\right.$ $0.05)$. There were no significant differences between Alloderm ${ }^{\circledR}(p=0.55)$ or fascia lata samples $(p=0.43)$.

Membrane diffusion coefficients were compared between groups using the nonparametric Kruskal-Wallis ANOVA and the Dunn post hoc tests $(p<0.05)$, because the distribution of these values was found not to be normally distributed, likely because of the small sample sizes (Table 3). The differences in the median diffusivity values between the three ECMs were not significantly different $(p=0.54)$.

Table 2. Effective Membrane Oxygen Diffusion Coefficients $\left(\mathcal{D}_{e, M}\right)$ of the Different Extracellular Matrices

\begin{tabular}{|c|c|c|c|}
\hline & SIS & Alloderm ${ }^{\circledR}$ & Fascia Lata \\
\hline Sample & Mean $\pm S E\left(\mathrm{~cm}^{2} / \mathrm{s}\right)$ & Mean $\pm S E\left(\mathrm{~cm}^{2} / \mathrm{s}\right)$ & Mean $\pm S E\left(\mathrm{~cm}^{2} / \mathrm{s}\right)$ \\
\hline 1 & $2 \pm 0.4 \times 10^{-5}$ & $1.1 \pm 0.1 \times 10^{-4 \S}$ & $2.4 \pm 0.4 \times 10^{-5}$ \\
\hline 2 & $1 \pm 0.4 \times 10^{-5}$ & $1.9 \pm 0.2 \times 10^{-5}$ & $1.6 \pm 0.2 \times 10^{-5}$ \\
\hline 3 & $1 \pm 0.2 \times 10^{-5}$ & $3.1 \pm 0.1 \times 10^{-5}$ & $2.3 \pm 0.2 \times 10^{-5}$ \\
\hline 4 & $8 \pm 4 \times 10^{-6}$ & $2.5 \pm 0.3 \times 10^{-5}$ & $4 \pm 0.4 \times 10^{-5}$ \\
\hline 5 & $7 \pm 4 \times 10^{-6}$ & & \\
\hline 6 & $9 \pm 2 \times 10^{-6}$ & & \\
\hline
\end{tabular}

The standard errors $\left(\mathrm{SE}_{\mathrm{s}}\right)$ for the effective membrane oxygen diffusion coefficients $\left(\mathcal{D}_{\mathrm{e}, \mathrm{M}}\right)$ were calculated using standard error propagation techniques. The diffusion coefficients are representative of the average value determined from the repeated measures $(n=3)$ for each sample. The SE estimations represent determinations at a $95 \%$ confidence interval.

${ }^{\S}$ The experimental conditions for this sample were not consistent with the assumptions of the diffusion cell model. The diffusion coefficient is reported for demonstrative purposes only, but was not considered in the subsequent statistical analyses (Table 3). 
Table 3. Effective Membrane Oxygen Diffusion Coefficients $\left(\mathcal{D}_{e, M}\right)$ (median, $25 \%$ and $75 \%$ interval)

\begin{tabular}{lcccc}
\hline Membrane Type & $N$ & Median $\left(\mathrm{cm}^{2} / \mathrm{s}\right)$ & $25 \%\left(\mathrm{~cm}^{2} / \mathrm{s}\right)$ & $75 \%\left(\mathrm{~cm}^{2} / \mathrm{s}\right)$ \\
\hline SIS (porcine) & 6 & $4.6 \times 10^{-5}$ & $7.0 \times 10^{-6}$ & $1.3 \times 10^{-5}$ \\
Alloderm ${ }^{-5}$ (human dermis) & 3 & $2.5 \times 10^{-5}$ & $2.1 \times 10^{-5}$ & $2.9 \times 10^{-5}$ \\
Fascia lata (canine) & 4 & $2.0 \times 10^{-5}$ & $1.7 \times 10^{-5}$ & $2.0 \times 10^{-5}$ \\
\hline
\end{tabular}

\section{Estimating critical scaffold thickness $\left(2 L_{z, \text { Critical. }}\right)$}

The smallest of the measured effective membrane diffusion coefficients $\left(\mathcal{D}_{e, M}\right)$ for each ECM were used to estimate critical scaffold thickness (SIS: $6.9 \times 10^{-6}$, Alloderm ${ }^{\circledR}$ : $1.9 \times 10^{-5}$, and fascia lata: $\left.1.6 \times 10^{-5} \mathrm{~cm}^{2} / \mathrm{s}\right)$. The critical tissue-thickness values $\left(2 L_{z, \text { Critical }}\right)$ for a range of oxygen substrate concentrations were determined (Fig. 6). Had thickness estimates been based on oxygen diffusivity in a protein solution $\left(2.69 \times 10^{-5} \mathrm{~cm}^{2} / \mathrm{s}\right)$ rather than the actual measured membrane diffusivities $\left(\mathcal{D}_{e, M}\right)$, the critical thickness would have been overestimated $23 \%$ to $113 \%$, depending on the scaffold material (Fig. 6).

\section{DISCUSSION}

To the best of our knowledge, oxygen diffusion coefficients for ECMs derived from SIS, dermis (Alloderm ${ }^{\circledR}$ ), and fascia lata have not been previously determined. Specifically, the range for the effective diffusion coefficients of all $3 \mathrm{ECMs}$ was found to be approximately $7 \times 10^{-6}-4 \times 10^{-5} \mathrm{~cm}^{2} / \mathrm{s}$. Of the different matrices, SIS tended to have the lowest oxygen diffusivity values and Alloderm ${ }^{\circledR}$ and fascia lata the highest. The values we have reported for these ECMs were within the range of those previously reported for other soft biological tissues (Table 4). For all ECM materials, the oxygen diffusion coefficients were similar to or up to one order of magnitude lower than the diffusivity of oxygen in water or a protein solution. The differences in the reported ranges are likely due to varying matrix structure porosity and tortuosity that is inherent in these tissues.

ECMs are natural biomaterials with distinct tissue structures that influence the magnitude and variability of effective oxygen diffusivity values. For instance, SIS consists of collagen fibers that are randomly and loosely oriented on the serosal surface and densely packed in a complex 3-dimensional array on the mucosal surface. Consequently, the porosity of SIS has been shown to

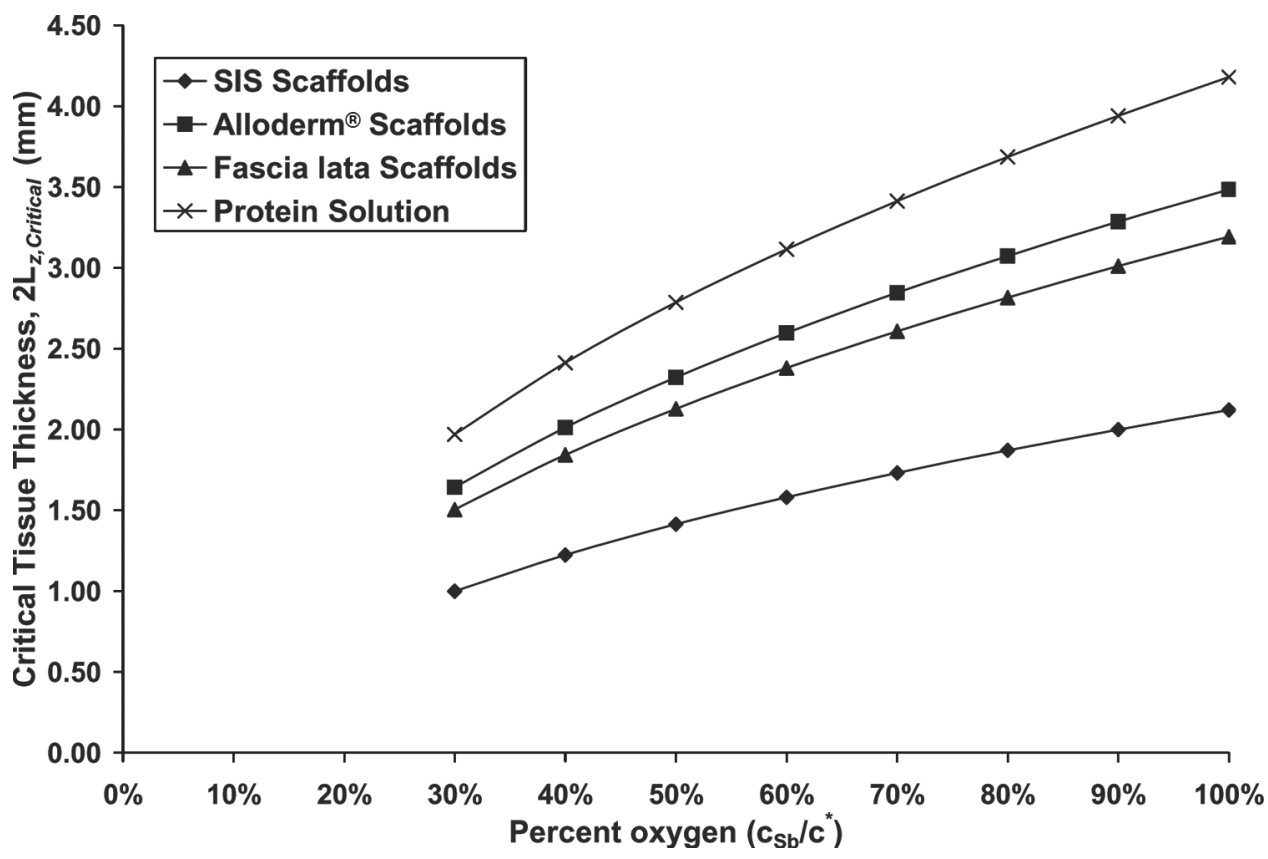

FIG. 6. Estimates of critical tissue thicknesses for cell-seeded small-intestinal submucosa (SIS), Alloderm ${ }^{\circledR}$ (dermis), and fascia lata scaffolds. The critical thickness is defined as the total thickness (i.e., $2 L_{z, \text { Critical. }}$ ) of a cell-seeded scaffold that would be adequately oxygenated via diffusive transport in vitro from both sides of the scaffold. The $x$-axis represents the percentage of oxygen based on the

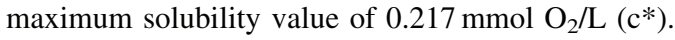


Table 4. Oxygen Diffusion Coefficients of Different Tissues

\begin{tabular}{ll}
\hline Tissue (ECM material) & \multicolumn{1}{c}{$\begin{array}{c}\text { Diffusion } \\
\text { Coefficient }\left(\mathrm{cm}^{2} / \mathrm{s}\right)\end{array}$} \\
\hline $\begin{array}{l}\text { SIS (porcine) } \\
\text { Alloderm }{ }^{\circledR}\end{array} \quad \begin{array}{l}7 \times 10^{-6}-2 \times 10^{-5} \\
\quad \text { human dermis) }\end{array}$ & $1.9-3.1 \times 10^{-5}$ \\
Fascia lata (canine) & $1.6-4 \times 10^{-5}$ \\
Aortic valve cusps & $1.06 \times 10^{-5}[23]$ \\
Cartilage & $4.0 \times 10^{-6}-2.5 \times 10^{-5}[16,24,25]$ \\
Muscle & $1.8-2.4 \times 10^{-5}[26-28]$ \\
\hline
\end{tabular}

Oxygen diffusion values reported for water:

Water at $37^{\circ} \mathrm{C} ; 3.83 \times 10^{-5} \mathrm{~cm}^{2} / \mathrm{s}[2]$

Protein Solution at $37^{\circ} \mathrm{C} ; 2.69 \times 10^{-5} \mathrm{~cm}^{2} / \mathrm{s}[5]$

decrease from the serosal (abluminal) surface to mucosal (luminal) surface of the ECM. ${ }^{11}$ Additionally, interspersed throughout the collagen network of SIS are remnant structures of blood vessels (tissue tags) and an occasional thick lymphoid tissue structure (Peyer's patch). Alloderm ${ }^{\circledR}$ consists of 2 layers, papillary dermis and reticular dermis, that differ in porosity. ${ }^{12,13}$ The papillary dermis is composed of randomly and loosely oriented collagen fibers, whereas the reticular layer is composed of dense collagen fiber bundles that form a complex 3-dimensional array. In addition, contained in both layers of the dermis are blood vessels, hair follicles, and glands. For SIS and Alloderm ${ }^{\circledR}$ (dermis), the within-group variability arose from distinct macroscopic tissue features (e.g., larger pores or vascular channels) that were observed in certain samples. It is likely that these tissue features provided additional pores and tunnels through which oxygen may have diffused.

Fascia lata is composed of superficial and deep collagen fascicle layers that are oriented obliquely to one another. Collagenous connective tissue holds the fascicles within each layer together. Unlike with SIS and Alloderm ${ }^{\circledR}$ (dermis), there are no prominent tissue features (e.g., glands, hair follicles, large blood vessels) inherent to fascia lata. The measured oxygen diffusivity of fascia lata is most likely representative of oxygen diffusion through the peri-fascicular connective tissue rather than through the dense collagen fascicles. In general, there was less variability in oxygen diffusivity from sample to sample within the fascia lata group, suggesting that the structure of fascia lata is more uniform than that of SIS or dermis. Larger sample sizes would be required to further investigate sample-to-sample variability within the different ECM materials.

Another factor contributing to the variability in the effective oxygen diffusivity within and between ECM materials is the variation in membrane thickness along the diameter of a single membrane, as well as between the ECM samples. The average membrane thickness determined from measurements made at 8 locations across the diffusion area was found to vary from $4 \%$ to $66 \%$ in the different membrane samples; a higher variation was observed in SIS samples than in Alloderm ${ }^{\circledR}$ and fascia lata samples because of remnant tissue structures, as described above. The variability in thickness was found to make the largest contribution to the standard error of the calculated effective diffusivities, accounting for $70 \%$ to $90 \%$ of the error in most cases. Having a uniform membrane thickness would improve the precision of the experimentally derived oxygen diffusion coefficients, although variable membrane thickness is fundamentally inherent to ECM membranes. Thus, the measurements presented here account for the uncertainty in membrane thickness and provide a representative range of oxygen diffusion coefficients of these 3 ECM materials.

It is possible that the presence of air bubbles and leakage of oxygen into the diffusion system limited our experimental membrane diffusivity measures. To address this, we measured and accounted for this baseline oxygen flux in our calculation of the effective membrane diffusivities. The baseline effect was approximately $20 \%$ for SIS, $53 \%$ for Alloderm ${ }^{\circledR}$, and $42 \%$ for fascia lata. Not accounting for this baseline flux would have resulted in a significant overestimation of the effective membrane diffusion coefficients.

The proposed model and experimental measurements for $\mathcal{D}_{e, M}$ can only be used to estimate a range of critical tissue thicknesses for these ECM membranes. Furthermore, the estimates of critical scaffold thickness are representative only of specific starting culture conditions. Over time in culture, we would expect that protein deposition could increase, thereby decreasing the scaffold diffusivity. ${ }^{3,14-16}$ The result would be a decrease in the critical construct thickness that could be maintained in culture. In addition, the oxygen consumption rates of the cell type used in a particular application would affect critical tissue thickness estimations. For example, cellular oxygen consumption rates reported in the literature range from $1.55 \times 10^{-9}$ to $3.80 \times 10^{-11} \mathrm{mmol} \mathrm{O}_{2} / \mathrm{h}$ per cell. $^{5,17-19}$ Thus, critical tissue-thickness values for cellseeded constructs with a higher oxygen consumption rates would result in construct values of $1 \mathrm{~mm}$ or less. Additionally, cell-seeded scaffold constructs that rely solely on diffusion for oxygen could eventually result in proliferation-dominated regions at the construct surface, thereby potentially resulting in oxygen levels at the interior that are well below the acceptable critical value. ${ }^{16,20-22}$ Not accounting for the effect of time in culture is a limitation of the current model system. A mathematical model that accounts for time-dependent culture transport limitations would be more realistic of oxygen kinetics and thereby improve on estimates of critical scaffold thickness values. Furthermore, the oxygen concentration of the bulk medium $\left(c_{S b}\right)$ will be dependent upon the particular bioreactor or culture system design. The medium at the surface of the construct in static culture system, which depends on surface aeration of the medium, will be less than fully oxygen saturated. In a static system, minimizing the distance between the construct and the air-medium interface can maximize available oxygen. In flow systems, which include a reservoir where medium is continuously sparged with air, the 
bulk medium concentration of oxygen can be legitimately assumed to equal the maximum saturation value of oxygen in the medium.

In summary, the effective membrane diffusion coefficients for the natural ECMs SIS, Alloderm ${ }^{\circledR}$ (dermis), and fascia lata have been determined. The data reported provide an understanding of the range and order of the effective diffusivity of the $3 \mathrm{ECMs}$, as well as the expected natural variation in this parameter within and between different ECM membranes. Use of these values in a critical tissuethickness model provides a means to estimate a practical limit on the size of cell-seeded scaffolds that can be cultured in vitro. However, these oxygen diffusivity coefficients are representative of only the initial material properties and culture conditions. Thus, the critical tissue thickness should be considered to be an initial estimate. Further characterizing how the ECM oxygen diffusivity changes with time in the presence of cells could provide more-rigorous estimates of critical construct thickness.

\section{NOMENCLATURE}

$A_{M}=$ Membrane surface area for diffusion $\left(\mathrm{cm}^{2}\right)$

$\beta^{\prime}=$ Effective membrane characteristic geometric constant $\left(/ \mathrm{cm}^{2}\right)$

$c^{*}=$ Maximum oxygen solubility in solution (at equilibrium with air) $(\mathrm{mg} / \mathrm{L})$

$c_{D}=$ Oxygen concentration in donor compartment $(\mathrm{mg} / \mathrm{L})$

$c_{R}=$ Solute (oxygen) concentration in receiver cell $(\mathrm{mg} / \mathrm{L})$

$c_{\mathrm{O} 2}=$ Local oxygen concentration at a specific $\mathrm{z}$ (mmol $\left.\mathrm{O}_{2} / \mathrm{L}\right)$

$c_{\mathrm{O} 2, \text { Critical }}=$ Critical oxygen level $\left(\mathrm{mmol} \mathrm{O}_{2} / \mathrm{L}\right)$

$c_{s b}=$ Oxygen concentration of the bulk medium (mmol $\left.\mathrm{O}_{2} / \mathrm{L}\right)$

$\mathcal{D}^{\prime}=$ "Diffusion" factor of the system (/s)

$\mathcal{D}_{\mathrm{e}, \mathrm{M}}=$ Effective membrane oxygen diffusion coefficient $\left(\mathrm{cm}^{2} / \mathrm{s}\right)$

$D_{B}=$ Experimental baseline oxygen volumetric diffusion factor $(\mathrm{L} / \mathrm{s})$

$j_{M}=$ Flux of solute (oxygen) per unit area from the membrane $\left(\mathrm{mg} / \mathrm{cm}^{2} \mathrm{~s}\right)$

$l=$ Membrane thickness $(\mathrm{cm})$

$L_{z, \text { Critical }}=$ One-half of the critical tissue thickness (mm)

$Q_{B}=$ Experimental baseline input rate of solute (oxygen) $(\mathrm{mg} / \mathrm{s})$

$q_{\mathrm{O} 2}=$ Specific oxygen uptake rate $\left(\mathrm{mol} \mathrm{O}_{2} /\right.$ hours cell $)$

$r_{\mathrm{O} 2}=$ Volumetric oxygen uptake rate $\left(\mathrm{mmol} \mathrm{O}_{2} /\right.$ hours $\mathrm{ml})$

$t=$ Time $(\mathrm{s})$

$\mathrm{V}_{\mathrm{R}}=$ Volume of receiver compartment (L)

$X=$ Cell density of the cell-seeded scaffold (cells $/ \mathrm{mL}$ )

$z=$ Distance $(\mathrm{cm})$

\section{ACKNOWLEDGMENTS}

Funding for this work was provided by Cleveland State University (CA, CSU Research Council's Doctoral Dissertation Research Expense Award 2004/2005) and the National Institutes of Health (KAD, R03-AR049858). SIS was generously provided by Dr. Steven BadylakMcGowan Institute for Regenerative Medicine, University of Pittsburgh, Alloderm ${ }^{\circledR}$ (human dermis) was generously provided by LifeCell Corporation, and fascia lata tissue was generously provided by Dr. Paul Murray, Center for Anesthesia Research, The Cleveland Clinic.

\section{REFERENCES}

1. Allen CB, Schneider BK, and White CW. Limitations to oxygen diffusion and equilibration in in vitro cell exposure systems in hyperoxia and hypoxia. Am J Physiol Lung Cell Mol Physiol 281, L1021, 2001.

2. Lee JM. Biochemical Engineering. Englewood Cliffs, N.J.: Prentice Hall, 1991.

3. Nehring D, Adamietz P, Meenen NM, and Porter R. Perfusion cultures and modeling of oxygen uptake with threedimensional chondrocyte pellets. Biotechnol Tech 13, 701, 1999.

4. Obradovic B, Carrier RL, Vunjak-Novakovic G, and Freed LE. Gas exchange is essential for bioreactor cultivation of tissue engineered cartilage. Biotechnol Bioeng 63, 197, 1999.

5. Peng CA, Palsson BO. Determination of specific oxygen uptake rates in human hematopoietic cultures and implications for bioreactor design. Ann Biomed Eng 24, 373, 1996.

6. Badylak SF, Lantz GC, Coffey A, Geddes LA. Small intestinal submucosa as a large diameter vascular graft in the dog. J Surg Res 47, 74, 1989.

7. Sandusky GE, Jr., Badylak SF, Morff RJ, et al. Histologic findings after in vivo placement of small intestine submucosal vascular grafts and saphenous vein grafts in the carotid artery in dogs. Am J Pathol 140, 317, 1992.

8. Cussler EL: Diffusion in dilute solutions. In: Diffusion: Mass Transfer in Fluid Systems. New York: Cambridge University Press, 1998, pp 15-28.

9. Nagarajan A, Garrido C, Morales W, Gatica JE. Phosphate reactions as mechanisms of high-temperature lubrication. NASA/TM 2006, 214060, 2006.

10. Froment GF, Hosten LH. Catalytic kinetics: modelling. Catalysis Sci Technol 2, 98, 1981.

11. Ferrand BK, Kokini K, Badylak SF, et al. Directional porosity of porcine small-intestinal submucosa. J Biomed Mater Res 27, 1235, 1993.

12. Craig AS, Eikenberry EF, Parry DA. Ultrastructural organization of skin: classification on the basis of mechanical role. Connect Tissue Res 16, 213, 1987.

13. Silver FH, Freeman JW, DeVore D. Viscoelastic properties of human skin and processed dermis. Skin Res Tech 7, 18, 2001.

14. Karande TS, Ong JL, Agrawal CM. Diffusion in musculoskeletal tissue engineering scaffolds: design issues related to porosity, permeability, architecture, and nutrient mixing. Ann Biomed Eng 32, 1728, 2004. 
15. Leddy HA, Awad HA, Wickham MQ, Guilak F. Molecular diffusion in tissue-engineered cartilage constructs: effects of time and culture conditions. 45th Annual Meeting, Orthopaedic Research Society, Anaheim, CA, 2003.

16. Malda J, Rouwkema J, Martens DE, et al. Oxygen gradients in tissue-engineered PEGT/PBT cartilaginous constructs: measurement and modeling. Biotechnol Bioeng 86, 9, 2004.

17. Balis UJ, Behnia K, Dwarakanath B, et al. Oxygen consumption characteristics of porcine hepatocytes. Metab Eng 1, 49, 1999.

18. Heywood HK, Bader DL, Lee DA. Rate of oxygen consumption by isolated articular chondrocytes is sensitive to medium glucose concentration. J Cell Physiol 206, 402, 2006.

19. Ruffieux PA, von Stockar U, Marison IW. Measurement of volumetric (OUR) and determination of specific $\left(\mathrm{qO}_{2}\right)$ oxygen uptake rates in animal cell cultures. J Biotechnol 63, 85, 1998.

20. Gross JD, Constantinidis I, Sambanis A. Modeling of encapsulated cell systems. J Theor Biol 244, 500, 2007.

21. Lewis MC, Macarthur BD, Malda J, et al. Heterogeneous proliferation within engineered cartilaginous tissue: the role of oxygen tension. Biotechnol Bioeng 91, 607, 2005.

22. Radisic M, Malda J, Epping E, et al. Oxygen gradients correlate with cell density and cell viability in engineered cardiac tissue. Biotechnol Bioeng 93, 332, 2006.

23. Weind KL, Boughner DR, Rigutto L, Ellis CG. Oxygen diffusion and consumption of aortic valve cusps. Am J Physiol Heart Circ Physiol 281, H2604, 2001.
24. Haselgrove JC, Shapiro IM, Silverton SF. Computer modeling of the oxygen supply and demand of cells of the avian growth cartilage. Am J Physiol 265, C497, 1993.

25. Obradovic B, Meldon JH, Freed LE, Vunjak-Novakovic G. Glycosaminoglycan deposition in engineered cartilage: experiments and mathematical model. AIChe J 46, 1860, 2000.

26. Meng H, Bentley TB, Pittman RN. Oxygen diffusion in hamster striated muscle: comparison of in vitro and near in vivo conditions. Am J Physiol 263, H35, 1992.

27. Bentley TB, Meng H, Pittman RN. Temperature dependence of oxygen diffusion and consumption in mammalian striated muscle. Am J Physiol 264, H1825, 1993.

28. Bentley TB, Pittman RN. Influence of temperature on oxygen diffusion in hamster retractor muscle. Am J Physiol 272, H1106, 1997.

Address reprint requests to: Kathleen A. Derwin, Ph.D. The Cleveland Clinic Department of Biomedical Engineering, ND20 9500 Euclid Avenue Cleveland, $\mathrm{OH} 44195$

E-mail: derwink@ccf.,org 
